\title{
Lypsylehmän kestävyyteen kannattaa panostaa
}

\author{
Anna-Maija Heikkilä ${ }^{1)}$, Jouni Nousiainen ${ }^{2)}$ ja Lauri Jauhiainen ${ }^{3)}$ \\ ${ }^{1)}$ MTT Taloustutkimus, Luutnantintie 13,00410 Helsinki, anna-maija.heikkila@mtt.fi \\ 2) MTT Kotieläintuotannon tutkimus, Halolantie 31 A, 71750 Maaninka, jouni.nousiainen@mtt.fi \\ ${ }^{3)}$ MTT Palveluyksikkö, 31600 Jokioinen, lauri.jauhiainen@mtt.fi
}

\section{Tiivistelmä}

Suomalaiset tarkkailulehmät poistetaan karjoista keskimäärin 4,9 vuoden iässä. Tällöin uudistuskustannus muodostaa noin neljänneksen maidontuotannon muuttuvista kustannuksista. Uudistuskustannuksen lisäksi lehmien kestävyydellä on vaikutusta jalostusvalinnan mahdollisuuteen, sukupolvien kiertonopeuteen sekä maitotuottoon ja eläinlääkintäkustannukseen. Uudistaminen vaikuttaa välillisesti myös naudanlihantuotantoon, sillä lypsylehmäkarjoissa ei ole varaa tehdä liharotusiemennyksiä silloin, kun lähes kaikki lehmävasikat tarvitaan uudistuseläimiksi.

Tutkimuksen tavoitteena oli määrittää lypsylehmien optimaalinen uudistuspolitiikka ja vertailla lehmän taloudellista arvoa kahden valtarotumme, ayrshiren ja holstein-friisiläisen, kesken. Tutkimuksessa laadittiin stokastinen optimointimalli, joka ratkaistiin dynaamista ohjelmointia hyväksi käyttäen. Mallin stokastiset elementit liittyivät lehmien tuotostasoon ja terveyteen. Mallissa ratkaistiin lypsykausittain, kannattaako eläintä vielä pitää tuotannossa, vai tulisiko se jo korvata uudella. Optimipäätösten lisäksi mallin tuloksena saatiin lehmästä odotettavissa olevien tuottojen nykyarvo.

Lehmien tuotos ja sen vaihtelu lypsykauden mukaan ennustettiin lehmien jalostusarvostelussa käytettävän koelypsymallin perusteella. Eläinlääkinnän tarve ja pakkopoiston riski määriteltiin lypsylehmien terveystarkkailuaineistosta. Sairauksien aiheuttamat tuotosmenetykset arvioitiin aikaisempien tutkimusten perusteella. Panosten ja tuotosten hintoina käytettiin ajankohdan markkinahintoja ja tuotantokustannuksia.

Suomalaisten lypsylehmien tuotantoiän pidentäminen on mahdollista, sillä vain noin puolet eläinten poistoista on luokiteltavissa pakollisiksi. Tutkimuksen tulokset antavat viitteitä siitä, että se on myös kannattavaa. Optimaalisella poistopolitiikalla ja oletetuilla pakkopoistoilla mallin karjan keskipoikimakerta vakiintui noin puolitoista poikimista nykyistä tarkkailukarjojen keskiarvoa suuremmaksi. Tilakohtaisesti optimaalinen uudistusnopeus riippuu muun muassa siitä, miten karja jakaantuu tuotoskyvyltään eri luokkiin. Vapaaehtoisesti kannattaa uudistaa vain karjan heikoimmat lehmät. Herkkyysanalyysi osoitti, ettei optimipäätös ole herkkä maidon tai tuotantopanosten hintamuutoksille. Lehmän arvoon hintamuutoksilla on kuitenkin suuri vaikutus.

Ennenaikaisiin poistoihin johtavia tapaturmia ja sairauksia tulisi ennaltaehkäistä maidontuotannon taloudellisen tuloksen parantamiseksi. Hoidettavissa olevat sairaudet kannattaa pääsääntöisesti hoitaa sen sijaan, että sairastunut lehmä korvattaisiin ensikolla. Pitkän aikavälin tarkastelussa ayrshirelehmän taloudellinen arvo on hieman suurempi kuin holstein-friisiläisen lehmän, jolla on korkeampi tuotos mutta suurempi riski sairastua tai tulla pakkopoistetuksi. Tulos osoittaa, että lypsylehmien jalostuksessa kannattaa tuotosominaisuuksien lisäksi antaa painoa myös lehmän kestävyysominaisuuksille.

Asiasanat: lehmät, uudistus, eläintaudit, dynaaminen optimointi 


\section{Johdanto}

Suomalaiset lypsylehmät poistetaan karjoista keskimäärin 4,9 vuoden ikäisinä. Vaikka poistoiän lasku tasaantui vuosituhannen vaihteessa, nykyinen poistoikä on noin kaksi vuotta alhaisempi kuin poistoikä neljä vuosikymmentä sitten. Nopea pudotus tapahtui 1990-luvun alkupuolella, jolloin maidon laatuvaatimukset kiristyivät oleellisesti (Kuva 1). Poistettaessa lehmät ovat ehtineet poikia vain kolme kertaa ja tuotantoikä eli ikä ensimmäisestä poikimisesta poistoon jää noin 2,7 vuoteen. Karjoissa olevien lehmien keskipoikimakerta on 2,3 .

Lyhyt tuotantoikä merkitsee korkeita uudistuskustannuksia, sillä noin kaksi vuotta kestävä uudistushiehon kasvatus maksaa keskikokoisissa lypsykarjoissa noin $2000 €$ (Juntti ja Heikkilä 2006). Niinpä uudistuskustannus muodostaa helposti jopa neljänneksen maidontuotannon muuttuvista kustannuksista. Uudistuskustannuksen lisäksi lehmien kestävyydellä on vaikutusta jalostusvalinnan mahdollisuuteen, sukupolvien kiertonopeuteen sekä maitotuottoon ja eläinlääkintäkustannukseen. Uudistaminen vaikuttaa välillisesti myös naudanlihantuotantoon, sillä lypsylehmäkarjoissa ei ole varaa tehdä liharotusiemennyksiä silloin, kun lähes kaikki lehmävasikat tarvitaan uudistuseläimiksi.

Koska karjan uudistuksen optimaalinen ajoitus edellyttää monien eri tekijöiden samanaikaista huomioon ottamista, päätöksenteon avuksi on kehitetty lukuisia optimointimalleja (Dohoo ja Dijkhuizen 1993, Lebenaur ja Oltjen 1998). Tämän tutkimuksen tavoitteena oli laatia suomalaiseen aineistoon perustuva ja suomalaisia hintasuhteita kuvaava uudistuksen optimointimalli. Suomalaisen terveystarkkailuaineiston ansiosta malliin voitiin sisällyttää myös eläinten riski sairastua tai tulla ennenaikaisesti poistetuksi. Laadittu stokastinen optimointimalli ratkaistiin dynaamista ohjelmointia hyväksi käyttäen. Mallin stokastiset elementit liittyivät sekä lehmän tuotospotentiaaliin että terveyteen. Mallissa ratkaistiin lypsykausittain, kannattaako eläintä vielä pitää tuotannossa, vai tulisiko se jo korvata uudella. Optimipäätösten lisäksi mallin tuloksena saatiin lehmästä odotettavissa olevien tuottojen nykyarvo, mikä mahdollisti lehmän taloudellisen arvon vertailun kahden valtarotumme, ayrshiren ja holstein-friisiläisen, kesken.

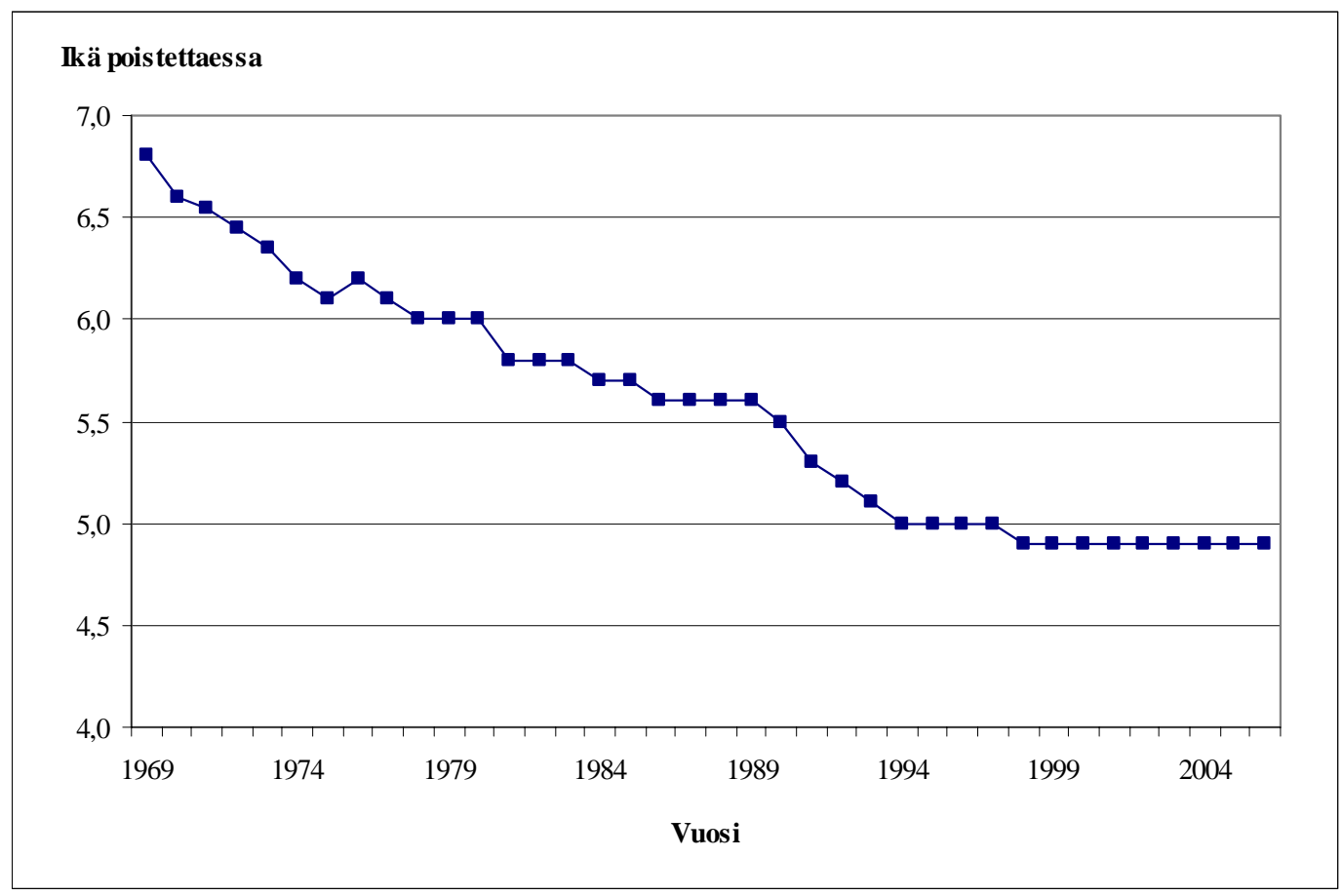

Kuva 1. Lypsylehmien keskimääräinen poistoikä tarkkailukarjoissa vuosina 1969-2006. 


\section{Aineisto ja menetelmät}

Optimointimallia varten tutkimuksessa määritettiin ensin lehmien tuotospotentiaali, eläinlääkinnän tarve ja pakollisen poiston riski roduittain kymmenelle ensimmäiselle lypsykaudelle. Tuotos ennustettiin koelypsymalliin perustuvilla tuotosfunktioilla (Lidauer ym. 2000, 2003) siten, että tuloksissa saatiin näkyviin eläinten perinnöllinen tuotospotentiaali ja poikimakerran vaikutus siihen. Tulokset osoittivat, että tuotos saavuttaa huippunsa viidennellä lypsykaudella ja kääntyy tämän jälkeen hitaasti laskuun. Tuotoksen kehitys oli samanlainen kummallakin rodulla, mutta holstein-friisiläisellä lehmällä tuotos oli noin $5 \%$ suurempi kuin ayrshirelehmällä. Tuotospotentiaalin geneettisen edistymisen ennustettiin olevan ayrshirelmillä $0,92 \%$ ja holsteinfriisiläislehmillä $1,05 \%$ vuodessa.

Rehunkulutus laskettiin lehmän tuotoksen ja elopainon mukaan ruokintanormien perusteella (MTT 2006). Rehuyhdistelmästä puolet oletettiin olevan karkearehua.

Eläinlääkinnän tarve määritettiin lypsylehmien terveystarkkailuaineistosta poimitusta otoksesta, jossa oli mukana 2102 karjan 61477 lehmää. Alueellisesti karjat edustivat Hämettä ja Etelä-Savoa. Tutkimusjakso kattoi ajan syyskuusta 2003 elokuuhun 2004. Ennaltaehkäiseviä toimenpiteet jätettiin tarkastelun ulkopuolelle. Tulosten mukaan keskimäärin 29 \% ayrshirelehmistä ja 32 \% holstein-friisiläislehmistä tarvitsi eläinlääkärin hoitoa tutkimusjakson aikana. Hoitokertojen tarve hoidettua lehmää kohti oli 1,5 kummallakin rodulla. Sekä hoidettujen lehmien osuus että hoitokertojen tarve lisääntyivät lehmän iän myötä.

Eläimen poiston pakollisuus määritettiin tutkimuksessa Nousiaisen (2006) esittämällä tavalla. Pakollisen poiston todennäköisyys määritettiin samoista karjoista, joista tutkittiin eläinlääkinnän tarvetta. Logistinen regressioanalyysi osoitti, että sekä rodulla että poikimakerralla oli tilastollisesti merkitsevä vaikutus $(P<$ $0,001)$ poiston pakollisuuteen (pakollinen vs. vapaaehtoinen poisto). Sen sijaan poiston todennäköisyyteen (poisto vs. karjassa säilyminen) ainoastaan poikimakerralla oli tilastollisesti merkitsevä vaikutus $(P<0,001)$. Kun todennäköisyys tulla poistetuksi kerrottiin poiston pakollisuuden todennäköisyydellä, saatiin tulokseksi mallissa tarvittu pakollisen poiston todennäköisyys. Todennäköisyys vaihteli poikimakerroittain ayrshirelehmillä välillä $0,09-0,26$ ja holstein-friisiläislehmillä välillä $0,10-0,28$ siten, että todennäköisyys kasvoi poikimakertojen myötä.

Maidon hintana mallissa käytettiin 0,425 €/l, lehmän lihan hintana 1,45 €/kg ja rehuyksikön keskihintana $0,22 € /$ ry. Uudistushiehon hinta arvioitiin sen kasvatuskustannuksen perusteella (Juntti ja Heikkilä 2006). Mallissa käytetyt hinnat, ayrshirehieho $1600 €$ ja holstein-friisiläishieho $1750 €$, vastasivat kustannusta noin 64 lehmän karjassa. Eläinlääkintä hinnoiteltiin Toivakan (2006) määrittämien hintojen painotettuna keskiarvona. Indeksikorotuksen jälkeen hoitokerran hinnaksi saatiin $80 €$. Sairauksista aiheutuvat tuotosmenetykset arvioitiin aikaisempien tutkimusten perusteella (Rajala ja Gröhn 1998, Rajala-Schultz ym. 1999a, b). Kutakin hoitokertaa kohti menetyksen keskimääräiseksi suuruudeksi arvioitiin 3 \% lypsykauden koko tuotoksesta. Mallin diskonttokerroin määritettiin maatalouden kannattavuuslaskelmissa yleisesti käytetyn 5 prosentin korkovaatimuksen mukaisesti.

Tutkimuksessa laaditulla mallilla etsittiin uudistuskäytäntöä, joka maksimoisi lehmän odotettavissa olevan nykyarvon. Lehmän arvo tarkoittaa tässä paitsi nykyisen lehmän arvoa, myös kaikkien niiden lehmien arvoa, jotka tulevat sen aikanaan korvaamaan (Miranda ja Fackler 2002). Uudistuksen ajoitus optimoitiin dynaamisen ohjelmoinnin avulla. Tämä matemaattinen menetelmä perustuu ns. Bellmanin optimaalisuusperiaatteeseen ja soveltuu tilanteisiin, joissa äärettömän pitkä optimointitehtävä voidaan pilkkoa periodeittain ratkaistaviksi ongelmiksi (Bellman 1957, Kennedy 1986, Bertsekas 2001).

Tässä tutkimuksessa ratkaistiin lypsykausittain, kannattaako lehmä pitää vielä tuotannossa vai poistaa ja korvata ensikolla. Lehmän tila kullakin periodilla määriteltiin kolmen muuttujan avulla: poikimakerta (1$10)$, tuotospotentiaali $(0,90,1,00,1,10)$ ja terveystilanne (terve, hoidettavissa oleva sairaus, pakolliseen poistoon johtava sairaus). Todennäköisyys saavuttaa seuraavalla periodilla tietty tila ilmaistiin tutkimusaineistosta määritettyjen todennäköisyysjakaumien avulla. Yhden periodin tuottofunktioon sisällytettiin maito- ja lihatuotto, rehu-, eläinlääkintä- ja uudistuskustannus sekä tuotosmenetysten ja geneettisen edistymisen arvo. Muut tuotot ja kustannukset oletettiin kiinteiksi. Malli ratkaistiin äärettömässä aikahorisontissa MATLABohjelman CompEcon-työkalua hyväksi käyttäen (Miranda \& Fackler 2002). 


\section{Tulokset ja tulosten tarkastelu}

Tulokset osoittivat, että vain vanhimpia, heikoimman tuotospotentiaalin omaavia lehmiä kannattaa poistaa vapaaehtoisesti. Saman tuotosryhmän sisällä optimipäätökset olivat samat eläimen terveystilasta huolimatta. Jos mallin tilamuuttujien määrittelemien erilaisten lehmien $(10 \times 3 \times 3)$ oletetaan muodostavan karjan, optimaalisten poistopäätösten ja oletettujen pakkopoistojen seurauksena keskipoikimakerraksi ayrshirekarjassa muodostui 3,8 ja holstein-friisiläiskarjassa 3,7. Vuosittain karjoista poistui vain noin 20 \% lehmistä, suurimmaksi osaksi pakottavista syistä.

Suurin nykyarvo saavutettiin parhaimman tuotospotentiaalin omaavilla lehmillä. Tuotosryhmän sisällä terveiden lehmien arvo oli suurin, ennenaikaisesti poistettaviksi joutuneiden pienin. Sairauksien aiheuttamat menetykset vaihtelivat 260 eurosta 480 euroon lypsykautta kohti. Pakkopoistojen aiheuttamat menetykset olivat huomattavasti suuremmat. Enimmillään tappio oli lähes 3000 euroa, kun terve, hyvätuotoksinen lehmä jouduttiin poistamaan ensimmäisen lypsykauden jälkeen. Lehmän keskimääräinen arvo oli ayrshirekarjassa hieman suurempi kuin holsteinfriisiläiskarjassa.

Optimipäätökset eivät olleet kovin herkkiä hintamuutoksille. Testatut \pm 20 prosentin hintamuutokset vaikuttivat lähinnä heikoimpien lehmien optimaaliseen uudistusnopeuteen; maidon hinnan nousu tai tuotantopanosten hinnan lasku nopeuttivat uudistusta, päinvastaiset muutokset lykkäsivät sitä. Lehmän arvoon hintamuutoksilla sen sijaan oli oleellinen vaikutus.

Tutkimuksen taustalla oli huoli lehmien lyhentyneestä tuotantoiästä ja tarve saada yleiskuvaa siitä, miten lehmien sairastuvuus ja ennenaikaisen poiston riski vaikuttavat toisaalta optimaaliseen uudistusnopeuteen, toisaalta lehmästä odotettavissa olevaan tuottoon. Mallissa ratkaistiin tämän vuoksi optimaalinen poistopäätös vain kokonaisten lypsykausien tasolla. Tarkempi optimointi lypsykauden sisällä edellyttäisi huomattavasti yksityiskohtaisemman mallin ja muuttujien kausivaihtelun huomioon ottamisen. Sairauksien tarkastelu kokonaistasolla ei myöskään vastaa yksittäisen poistopäätöksen tueksi laadittavan mallin vaatimuksia. Mallin yksinkertaisuudesta huolimatta tulokset vastasivat hyvin niiden harvojen aikaisempien tutkimusten tuloksia, joissa sairausriski on ollut mukana (Stott ja Kennedy 1993, Houben ym. 1994, Stott ym. 2002, Gröhn ym. 2003).

\section{Johtopäätökset}

Suomalaisten lypsylehmien tuotantoiän pidentäminen on mahdollista, sillä vain vajaa puolet eläinten poistoista on luokiteltavissa pakollisiksi. Tutkimuksen tulokset antavat viitteitä siitä, että se on myös kannattavaa. Optimaalisella poistopolitiikalla ja oletetuilla pakkopoistoilla mallin karjan keskipoikimakerta vakiintui noin puolitoista poikimista nykyistä tarkkailukarjojen keskiarvoa suuremmaksi. Tilakohtaisesti optimaalinen uudistusnopeus riippuu muun muassa siitä, miten karja jakaantuu tuotoskyvyltään eri luokkiin. Vapaaehtoisesti kannattaa uudistaa vain karjan heikoimmat lehmät.

Optimipäätökset eivät olleet herkkiä maidon tai tuotantopanosten hintamuutoksille. Lehmän arvoon hintamuutoksilla oli kuitenkin suuri vaikutus. Tämä osoittaa, että pelkän uudistuspolitiikan avulla ei voida sopeutua hintamuutoksiin; optimaalisella politiikalla voidaan ainoastaan lieventää epäedullisten hintasuhteiden vaikutusta tuotannon kannattavuuteen.

Ennenaikaisiin poistoihin johtavia tapaturmia ja sairauksia tulisi ehkäistä maidontuotannon taloudellisen tuloksen parantamiseksi. Hoidettavissa olevat sairaudet kannattaa pääsääntöisesti hoitaa sen sijaan, että sairastunut lehmä korvattaisiin ensikolla. Pitkän aikavälin tarkastelussa ayrshirelehmän taloudellinen arvo on hieman suurempi kuin holstein-friisiläisen lehmän, jolla on korkeampi tuotos mutta suurempi riski sairastua tai tulla pakkopoistetuksi. Tulos osoittaa, että lypsylehmien jalostuksessa kannattaa tuotosominaisuuksien lisäksi antaa painoa myös lehmän kestävyysominaisuuksille.

\section{Kirjallisuus}

Bellman, R. E. 1957. Dynamic Programming. Princeton University Press, Princeton, NJ. 339 p.

Bertsekas, D. P. 2001. Dynamic Programming and Optimal Control. Volume 2: Dynamic Programming. 2nd edition. Athena Scientific, Belmont, MA. 303 p.

Dohoo, I. R. \& Dijkhuizen, A. A. 1993. Techniques involved in making dairy cow culling decisions. Compend. Contin. Educ. Pract. Vet. 15:515-519. 
Gröhn, Y. T., Rajala-Schultz, P. J., Allore, H. G., DeLorenzo, M. A., Hertl, J. A. \& Galligan, D. T. 2003. Optimizing replacement of dairy cows: modeling the effects of diseases. Prev. Vet. Med. 61:27-43.

Houben, E. H. B., Huirne, R. B. M., Dijkhuizen, A. A. \& Kristensen, A.R. 1994. Optimal replacement of mastitic cows determined by a hierarchic Markov process. J. Dairy Sci. 77:2975-2993.

Juntti, L. \& Heikkilä, A-M. 2006. Uudistushiehon tuotantokustannus. In: Heikkilä, Anna-Maija (toim.). Kestävä lehmä. Lypsylehmien poiston syyt ja kestävyyden taloudellinen merkitys. MTT:n selvityksiä 112: 48-51. Verkkojulkaisu päivitetty 2.5.2006. [viitattu 8.8.2007]. Saatavissa: http://www.mtt.fi/mtts/pdf/mtts112.pdf .

Kennedy, J. O. S. 1986. Dynamic Programming: Applications to Agriculture and Natural Resources. Elsevier Applied Science Publishers, London, UK. 341 p.

Lehenbauer, T. W. \& Oltjen, J. W. 1998. Dairy cow culling strategies: making economical culling decisions. J. Dairy Sci. 81:264-271.

Lidauer, M., Mäntysaari, E. A. \& Strandén, I \& Pösö, J. 2000. Multiple-trait random regression test-day model for all lactations. Interbull Bulletin 25. Proceedings of the 2000 Interbull meeting Bled, Slovenia May 14-15, 2000:81-86.

Lidauer, M., Mäntysaari, E. A. \& Strandén, I. 2003. Comparison of test-day models for genetic evaluation of production traits in dairy cattle. Livest. Prod. Sci. 79:73-86.

Miranda, M. J. \& Fackler, P. L. 2002. Applied Computational Economics and Finance. MIT Press, Cambridge, MA. $510 \mathrm{p}$.

MTT 2006. Rehutaulukot ja ruokintasuositukset [verkkojulkaisu]. Jokioinen: Maa- ja elintarviketalouden tutkimuskeskus. Julkaistu 14.2.2006, [viitattu 8.8.2007]. Saatavissa: http://www.agronet.fi/rehutaulukot.

Nousiainen, J.I. 2006. Lypsylehmien poiston syyt. In: Anna-Maija Heikkilä (toim.). Kestävä lehmä. Lypsylehmien poiston syyt ja kestävyyden taloudellinen merkitys. MTT:n selvityksiä 112: 9-26. Verkkojulkaisu päivitetty 2.5.2006. [viitattu 8.8.2007] Saatavissa: http://www.mtt.fi/mtts/ pdf/mtts112.pdf.

Rajala, P. J. \& Gröhn, Y. T. 1998. Effects of dystocia, retained placenta, and metritis on milk yield in dairy cows. J. Dairy Sci. 81:3172-3181.

Rajala-Schultz, P. J., Gröhn, Y. T. \& McCulloch, C. E. 1999a. Effects of milk fever, ketosis, and lameness on milk yield in dairy cows. J. Dairy Sci. 82:288-294.

Rajala-Schultz, P. J., Gröhn, Y. T., McCulloch, C. E. \& Guard, C. L. 1999b. Effects of clinical mastitis on milk yield in dairy cows. J. Dairy Sci. 82:1213-3181.

Stott, A. W. \& Kennedy, J. O. 1993. The economics of culling dairy cows with clinical mastitis. Vet. Rec. 133:494499.

Stott, A. W., Jones, G. M., Gunn, G. J., Chase-Topping, M., Humphry, R. W, Richardson, H. \& Logue, D. N. 2002. Optimum replacement policies for the control of subclinical mastitis due to S.aureus in dairy cows. J. Agric. Econ. 53:627-644.

Toivakka, M. 2006. Lypsykarjan tuotanto-, hedelmällisyys- ja terveysominaisuuksien taloudelliset arvot. In: AnnaMaija Heikkilä (toim.). Kestävä lehmä. Lypsylehmien poiston syyt ja kestävyyden taloudellinen merkitys. MTT:n selvityksiä 112: 60-74. Verkkojulkaisu päivitetty 2.5.2006. [viitattu 8.8.2007] Saatavissa: http://www.mtt.fi/mtts/ pdf/mtts112.pdf. 